\title{
Survey of the decontamination and maintenance of dental handpieces in general dental practice
}

\author{
G. W. G. Smith, ${ }^{1}$ A. J. Smith, ${ }^{2}$ S. Creanor, ${ }^{3}$ D. Hurrell, ${ }^{4}$ J. Bagg ${ }^{5}$ \\ and D. F. Lappin ${ }^{6}$
}
IN BRIEF
- Uses robust methodology to provide a useful insight into dental handpiece decontamination.
- Demonstrates that $97 \%$ of dental surgeries studied autoclaved their handpieces between patients.
- The variety in processes for cleaning, lubricating, packing and sterilisation suggests that handpiece manufacturers need to clarify and validate their reprocessing instructions.

\begin{abstract}
Objectives To determine how dental handpieces are decontaminated and maintained in general dental practice. Design Observational survey. Setting The survey was carried out in general dental practice in Scotland. Survey visits ran from January 2003 until the end of March 2004. Methods Data were collected by interview and observation in 179 dental surgeries in Scotland. Results In virtually all surgeries, handpieces were cleaned before disinfection or autoclaving (99\%; $n=177)$, most commonly by wiping the external surface with a cloth impregnated with disinfectant. Most surgeries lubricated their handpieces after cleaning and before sterilisation ( $91 \% ; n=162)$, although a number of surgeries $(24 \% ; n=42)$ also lubricated their handpieces after sterilisation. In the majority $(97 \% ; n=174)$ of dental surgeries, all handpieces were autoclaved after use, most frequently $(89 \% ; n=160)$ in a bowl and instrument steriliser. In 38 surgeries $(21 \%)$, handpieces were being wrapped (paper pouches) before sterilisation in bowl and instrument sterilisers. A minority of surgeries $(20 \% ; n=36)$ had a dedicated handpiece for surgical procedures. Conclusions: The majority of dental handpieces are manually cleaned externally with a disinfectant impregnated cloth and processed in a type N (bowl and instrument) bench top steam steriliser. Handpieces are lubricated with non-water soluble lubricants at different stages of reprocessing, indicating clarification is required in this area. More work is required by manufacturers to establish a validated cleaning and lubrication process to facilitate the sterilisation of handpieces.
\end{abstract}

\section{INTRODUCTION}

The introduction of both high and slow speed dental handpieces has revolutionised dental treatment, allowing for significant improvements in restorative dentistry and patient care. Their use has, however, been accompanied by significant controversies regarding their potential for cross-infection $^{1-3}$ and the methods available for their effective disinfection or sterilisation. . $^{4-6}$

Although autoclavable handpieces became more readily available in the 1980s, the main method for decontaminating handpieces continued to be disinfection (of the external surfaces) rather than

\footnotetext{
${ }^{1} \mathrm{PhD}$ Student, ${ }^{2+}$ Senior Lecturer in Microbiology, ${ }^{5}$ Professor of Clinical Microbiology, ${ }^{6}$ Research Fellow, Infection Research Group, Level 9, Glasgow Dental Hospital and School, 378 Sauchiehall Street, Glasgow, G2 3JZ; ${ }^{3}$ Lecturer in Health Statistics, Biostatistics and Epidemiology Group, University of Plymouth, Tamar Science Park, Plymouth, PL6 8BX; ${ }^{4}$ Authorised Person (Sterilisers), HealthCare Science Limited, Bury Mead Road, Hitchin, Hertfordshire, SG5 1RT

${ }^{*}$ Correspondence to: $\operatorname{Dr}$ A. J. Smith

Tel: +44 (0)141 211 9741; Fax: +44 (0)141 3531593

Email:a.smith@dental.gla.ac.uk
}

\section{Online article number E7}

Refereed Paper - accepted 1 May 2009

DOI: 10.1038/sj.bdj.2009.761

${ }^{\circledR}$ British Dental Journal 2009; 207: E7 sterilisation. $^{7}$ In the 1990 s, particularly following the highly publicised case of HIV transmission in a Florida dental practice, attention was drawn to the potential for cross-infection by dental handpieces. Laboratory studies demonstrated aspiration of both dye and microorganisms into the air and water lines and the handpiece chamber, and their subsequent recovery following re-use of the high speed handpiece. ${ }^{1,8}$

Concerns over handpiece contamination relate to the accumulation of particulate matter (débris from restorative materials and dental hard tissues), ${ }^{9}$ microorganisms from the oral cavity (bacteria, fungi and viruses), ${ }^{2,10}$ microorganisms from the water and airlines ${ }^{11,12}$ and collection of human tissue (blood, saliva) ${ }^{1}$ within the handpiece chamber, turbine blades, gearing, air and water lines. Dental handpieces are extremely difficult to clean, inspect and sterilise due to the small size and length of lumens, intricate working parts (which require lubrication) and their inability to be readily dismantled. Current recommendations are that dental handpieces should be sterilised between patients. ${ }^{13-15}$ For sterilisation to be effective it should be performed following cleaning which, if inadequately performed, will compromise the sterilisation process. ${ }^{16}$ Efficient cleaning and lubrication are also important determinants of handpiece functionality and longevity. ${ }^{17}$ The adherence of dental practitioners to the recommendations for sterilising dental handpieces has, to date, been investigated using postal questionnaires with varying response rates. ${ }^{18-20}$ In order to address the shortcomings of previous questionnaire surveys, we have previously described a methodology for a large observational study of decontamination of dental instruments in general dental practice. ${ }^{21}$ The aim of the present paper is to report in detail the methods used for decontamination of dental handpieces in general dental practices and the procedures in place for purchase and maintenance of handpieces, as recorded using an observational method.

\section{MATERIALS AND METHODS}

\section{Survey methodology}

The survey was conducted according to the previously described method. ${ }^{21}$ The study population comprised all general dental 
practitioners in Scotland with a National Health Service (NHS) list number. The list was used for randomly selecting practitioners to survey. A total of 184 surgeries were surveyed, with usable data obtained from 179 surgeries.

\section{Data collection}

Each surgery was surveyed by an infection control/decontamination expert and an experienced dental practitioner. The surveying team interviewed both the dental practitioner and dental nurse. This survey was concerned with collecting data relating to dental handpieces, in particular: the selection, procurement, cleaning, lubrication, sterilisation, maintenance and replacement of air turbines and air rotors. The decontamination processes undertaken by the surgery nurse were viewed directly by a member of the survey team. All data were recorded onto data collection forms prepared for automated reading. ${ }^{21}$ The survey visits ran from January 2003 until the end of March 2004.

\section{Technical requirements and guidance}

The information recorded on the data collection forms was based on a number of technical requirements and guidelines including SHTM 2030,22 HTM 2030,23 the Glennie Framework, ${ }^{24}$ the Medical Devices Regulations 2002, ${ }^{25}$ the Health and Safety at Work Act $1974^{26}$ and Management of Health and Safety at Work Regulations 1992.. ${ }^{27}$

\section{RESULTS}

\section{Dental handpiece purchasing and maintenance}

Of the 179 dental surgeries surveyed, 95\% ( $\mathrm{n}=170$ ) had no written policy for purchasing handpieces. The member of surgery staff with responsibility for handpiece purchase was the principal/ partner of the practice in 97\% $(n=174)$ of surgeries, 102 (59\%) of whom did not seek information on handpiece decontamination before purchase. In the vast majority of surgeries $(96 \% ; n=172)$, all new handpieces were decontaminated before first use.

The most common air turbine brand held by the dental surgeries surveyed was Kavo (Table 1). Most surgeries (77\%; n

Table 1 Types of air turbines, electric motors and handpieces used in surgeries

\begin{tabular}{|c|c|c|c|c|}
\hline Brand of air turbine & $\begin{array}{l}\text { Number of } \\
\text { surgeries with } \\
\text { type of turbine/ } \\
\text { handpiece }\end{array}$ & $\begin{array}{l}\text { Median number } \\
\text { of handpieces } \\
\text { per surgery }\end{array}$ & $\begin{array}{l}\text { Range of } \\
\text { number of } \\
\text { handpieces per } \\
\text { surgery }\end{array}$ & $\begin{array}{l}\text { Total number } \\
\text { of handpieces } \\
\text { across surgeries }\end{array}$ \\
\hline Bien Air & 12 & 3 & $0-6$ & 35 \\
\hline KaVo & 91 & 4 & $0-9$ & 341 \\
\hline NSK & 64 & 3 & $0-16$ & 221 \\
\hline Star Dental & 12 & 3 & $0-4$ & 18 \\
\hline WEH & 41 & 3 & $0-6$ & 106 \\
\hline Other & 18 & 3 & $0-5$ & 54 \\
\hline \multicolumn{5}{|c|}{ Contra angle handpieces } \\
\hline Bien Air & 14 & 3 & $0-6$ & 39 \\
\hline KaVo & 58 & 3 & $0-8$ & 190 \\
\hline NSK & 97 & 4 & $0-12$ & 381 \\
\hline Star Dental & 1 & 7 & $0-7$ & 7 \\
\hline WEtH & 60 & 3 & $0-9$ & 156 \\
\hline Other & 18 & 2 & $0-6$ & 39 \\
\hline \multicolumn{5}{|c|}{ Slow straight handpieces } \\
\hline Bien Air & 11 & 1 & $0-2$ & 5 \\
\hline KaVo & 52 & 1 & $0-2$ & 55 \\
\hline NSK & 87 & 1 & $0-8$ & 126 \\
\hline Star Dental & 0 & - & - & - \\
\hline WEtH & 35 & 1 & $0-3$ & 36 \\
\hline Other & 18 & 1 & $0-2$ & 18 \\
\hline
\end{tabular}

\section{Table 2 Methods reported for cleaning handpieces}

\begin{tabular}{l|l} 
Method & Number (\%) of surgeries* \\
\hline Wipe external surface with cloth & $33(18.4)$ \\
\hline Wipe external surface with disinfectant impregnated cloth & $85(47.5)$ \\
\hline Place in 'Assistina' & $5(2.8)$ \\
\hline Place in washer disinfector & $1(0.6)$ \\
\hline Place in ultrasonic bath & $10(5.6)$ \\
\hline Other (unspecified method) & $62(34.6)$ \\
\hline *Some surgeries used more than one cleaning method &
\end{tabular}

= 138) had purchased a new air turbine handpiece within the last 12 months and the majority of surgeries $(62 \% ; n=111)$ had serviced their air turbines within the last 12 months. The most common brand of slow speed (contra-angle) and straight handpiece was NSK (Table 1). Most surgeries $(88 \% ; n=157)$ had no written maintenance policy for handpieces and only a minority $(27 \% ; n=49)$ performed their own handpiece maintenance.

\section{Handpiece cleaning}

Virtually all surgeries cleaned handpieces before disinfection or autoclaving (99\%; $n=177)$. The most common method of handpiece cleaning used was to wipe the external surface with a cloth 
impregnated with disinfectant (Table 2). In a small number of surgeries (3\%; $n$ $=5$ ), irrigation of the internal lumen of the handpiece was undertaken. Following cleaning, the majority of surgeries (92\%; $\mathrm{n}=165$ ) inspected the external surface of the handpiece for cleanliness and 25\% ( $n=44$ ) of surgeries dried the handpiece before sterilisation, usually by wiping with a paper towel or leaving to air dry in the surgery.

\section{Lubrication of handpieces}

Staff in some surgeries $(20 \% ; \mathrm{n}=36)$ lubricated their handpieces following use and before cleaning. Most lubricated handpieces after cleaning but before sterilisation $(91 \% ; n=162)$, although a number $(24 \% ; n=42)$ lubricated again after sterilisation. Most surgeries used the handpiece manufacturers' recommended lubricant, none of which were water soluble (source: manufacturers' material safety data sheets and websites). ${ }^{28-30}$

\section{Handpiece autoclaving}

The policy in virtually all of dental surgeries $(97 \% ; n=174)$ was to autoclave all handpieces after use, with most (89\%; n $=160$ ) reprocessing handpieces in a bowl and instrument steriliser. Staff in some surgeries $(21 \% ; n=38)$ were placing their handpieces in paper pouches before sterilisation in a bowl and instrument steriliser.

\section{Storage and use of handpieces}

Within the surgeries most handpieces were stored in a dry and secure location, although a number $(31 \% ; n=55)$ were stored on open work surfaces. Before use, dentists in most surgeries $(71 \% ; n=127)$ discharged their handpieces to dissipate excess lubricant and some $(31 \% ; n=55)$ discharged their handpieces for several seconds after use on each patient to reduce the likelihood of aspiration of patient material into the handpiece. A minority of surgeries $(20 \% ; n=36)$ had a dedicated handpiece for surgical procedures.

\section{DISCUSSION}

The results of this survey provide a valuable insight into handpiece decontamination in general dental practice in Scotland. The data were obtained by observing and interviewing dentists and dental nurses in a large number of practices, as opposed to data collection using postal questionnaires. ${ }^{18-20}$ It was reassuring to find that the vast majority of dental surgeries now autoclave dental handpieces after use. Before the intense media coverage of handpiece sterilisation in the early 1990s, large numbers of dentists disinfected rather than sterilised their handpieces. Studies of dental practitioners in England, reported in 1995, indicated that between $46 \%$ (response rate of 53\% of 500 practitioners) ${ }^{18}$ and $77 \%$ (response rate of 74\% from 312 practitioners $)^{19}$ of practitioners were sterilising handpieces between patients and our data suggest that compliance with this policy has continued to improve. Nevertheless, a more recent survey of 700 GDPs in the Republic of Ireland (response rate of $40 \%$ ) reported that 53\% did not autoclave their handpiece between patients, indicating continued reluctance in some areas to embrace the need for handpiece sterilisation. $^{20}$

Dental handpieces present a particular problem for decontamination because they have both external and internal surfaces that become contaminated during clinical use. When the air and water delivered to the handpiece during operation are switched off, the temporary negative pressure induced is likely to result in retraction of contaminated fluid and air along the air and water lines into the handpiece. ${ }^{1,2}$ As a result, the lumen and the turbine blades of the handpiece become contaminated with oral secretions, which may include restorative materials and biological debris such as microorganisms, saliva, blood and tissue debris. In addition, the air and water lines, turbine and drive shafts can be contaminated from the source of the compressed air and water supply. Dental handpieces are used for a wide variety of dental interventions, some of which can be classified as critical, ${ }^{15}$ and as such handpieces should be sterile when used. Guidance from a number of organisations has recommended that all dental handpieces should be sterilised between patients. ${ }^{13-15}$

In order to facilitate handpiece sterilisation and improve the longevity of the handpiece, a critical control point in the decontamination process is effective cleaning. ${ }^{31}$ At present there do not appear to be any validated cleaning processes for dental handpieces. Further challenges of handpiece decontamination include the necessity for air removal from the lumens to allow steam penetration, necessitating use of a forced air removal stage during the sterilisation cycle, ie using a vacuum steriliser. ${ }^{13,31,32}$ The wrapping of dental handpieces and processing in a non-vacuum steriliser will also impede the penetration of steam into the device. ${ }^{32}$ This practice was identified in a number of practices in this survey. At present, vacuum steam sterilisers are not widely used in dental practice in the UK. ${ }^{33}$

The stage in the decontamination cycle at which handpiece lubrication was undertaken varied considerably, suggesting some confusion in this area. The handpiece manufacturers recommend lubricating after cleaning and before sterilisation, although the data from the current study indicates that non-water soluble lubricant is quite commonly supplied by the manufacturers. The use of non-water soluble lubricants can impair steam penetration into the surfaces of the handpiece and there is the possibility that such oil-based lubricants could prevent the steam from killing bacterial spores., ${ }^{4,1631}$

Thus, there are many technological challenges to overcome before general practitioners have the facility to introduce processes that will reliably deliver sterile handpieces. In the interim, it appears that cleaning the external surface and autoclaving handpieces after each patient is a regular feature of infection control processes in general dental practice.

In conclusion, using a robust, observational method of data collection, the policy in the majority of dental surgeries examined is to autoclave handpieces between patients as a routine element of the infection control protocol. This is a very positive development in recent years and one which significantly enhances patient safety. However, a number of technological issues remain to be resolved before manufacturers' claims that handpieces are sterile can be substantiated. Foremost among these is a validated cleaning process coupled with appropriate lubrication of the internal components, development of which are the responsibility of handpiece manufacturers. An effectively cleaned handpiece would then require to be sterilised under vacuum conditions to satisfy criteria for such devices to be labelled as sterile. Use of a vacuum steriliser would have additional 
advantages of allowing handpieces to be wrapped before and during sterilisation, thereby preventing the possibility of environmental recontamination and clearly distinguishing processed from unprocessed instruments. However, the widespread introduction of vacuum steam sterilisers into general dental practices remains a contentious issue due to increased capital, revenue costs and technical requirements for periodic testing.

1. Lewis D L, Boe R K. Cross-infection risks associated with current procedures for using high-speed dental handpieces. J Clin Microbiol 1992; 30: 401-406.

2. Lewis D L, Arens M, Appleton S S et al. Cross-contamination potential with dental equipment. Lancet 1992; 340: 1252-1254.

3. Epstein J B, Rea G, Sherlock C H, Mathias R G. Continuing investigation and controversy regarding risk of transmission of infection via dental handpieces. J Can Dent Assoc 1996; 6: 485-491.

4. Edwardsson S, Svensatar G, Birkhed D. Steam sterilisation of air turbine dental handpieces. Acta Odonto/ Scand 1983; 41: 321-326.

5. Kolstad R A. How well does the Chemiclave sterlize handpieces? J Am Dent Assoc 1998; 129: 985-991.

6. Parker $\mathrm{H}_{\mathrm{H}}$, Johnsson R B. Effectiveness of ethylene oxide for sterilisation of dental handpieces. J Dent 1995; 23: 113-115.

7. Bray F, Chapman S. AIDS and dentistry in Australia: knowledge, infection control practices and attitudes to treatment in a random sample of Australian dentists. Community Health Stud 1990; 14: 384-393.

8. Checchi L, Montebugnoli L, Samaritani S.

Contamination of the turbine air chamber: a risk of cross infection. J Clin Periodontol 1998; 8: 607-611.
9. Pelzner R B, Kempler D, Stark M M, Barkin P R, Graham D A. Laser evaluation of handpiece contamination. J Dent Res 1977; 56: 1629-1634.

10. Kellet M, Holbrook W P. Bacterial contamination of dental handpieces. J Dent 1980; 8: 249-253.

11. Abel L C, Miller R L, Micik R E, Rige G. Studies on dental aerobiology: $\mathrm{VI}$. Bacterial contamination of water delivered by dental units. J Dent Res 1971; 50: 1567-1569.

12. Walker J T, Bradshaw D J, Bennett A M et al. Microbial biofilm formation and contamination of dental-unit water systems in general dental practice. Appl Environ Microbio/ 2000; 66: 3, 363-363, 367

13. Medical Devices Agency. Sterilisation, disinfection and cleaning of medical equipment: Guidance on decontamination from the Microbiology Advisory Committee to Department of Health. Section 2. London: The Stationery Office. 2002.

14. British Dental Association. Advice Sheet A12. London: British Dental Association, 2003.

15. Kohn W G, Collins A S, Cleveland J L, Harte J A, Eklund K J, Malvitz D M; Centres for Disease Control and Prevention(CDC). Guidelines for infection control in dental health care settings - 2003 MMWR Recomm Rep 2003; 52(RR-17): 1-61.

16. Pflug I J, Holcomb R G, Gomez M M. Principles of the thermal destruction of microorganisms. In Block S S (ed) Disinfection, sterilisation and preservation. 5th ed. Philadelphia: Lippincott, Williams \& Wilkins, 2001.

17. Leonard D L, Charlton D G. Performance of high-speed dental handpieces subjected to simulated clinical use and sterilisation. JAm Dent Assoc 1999; 130: 1301-1311.

18. Lloyd L, Burke F J, Cheung S W. Handpiece asepsis: a survey of the attitudes of dental practitioners. Br Dent J 1995; 178: 23-27.

19. Bentley E M, Sarll D W. Improvements in cross infection control in general dental practice. Br Dent J 1995; 179: 19-20.

20. Healy C M, Kearns H P O, Coulter W A, Stevenson
M, Burke F J T. Autoclave use in dental practice in the Republic of Ireland. Int Dent J 2004 54: 182-186.

21. Smith A, Hurrell D, Bagg J, McHugh S, Mathewson $H$, Henry M A. A method for surveying instrument decontamination procedures in general dental practice. Br Dent J 2007; 202: E20.

22. NHS Scotland Property and Environmental Forum. SHTM 2030: Washer disinfectors. Edinburgh: HMSO, 2001

23. NHS Estates. HTM 2030: Washer disinfectors. Edinburgh: HMSO, 1997.

24. NHS Scotland. Sterile Services Provision Review Group: first report - The Glennie Framework. Edinburgh: NHS Scotland, 2001.

25. Medical Devices Regulations. Londond: HMSO, 2002.

26. Health and Safety at Work Act 1974. London: HMSO, 1974.

27. The Management of Health and Safety at Work Regulations 1999. London: HMSO, 1999.

28. KaVo care systems and materials webpage http://www.kavo.com/En/produkte/pflege/pflege. asp?navid=6000\&tlan=En (accessed 31 July 2009)

29. Direct Turbine handpiece maintenance guide webpage. http://www.directturbine.com/ maintenance guide.html (accessed 31 July 2009).

30. WEtH International sterilization, hygienic and maintenance webpage. http://www.wh.com/en_ global/products/hygienicmaintenance/ accessed 31 July 2009).

31. Andersen H K, Fiehn N E, Larsen T. Effect of steam sterilisation inside the turbine chambers of dental turbines. Oral Surg Oral Med Oral Pathol Oral Radiol Endod 1999; 87: 184-188.

32. Medical Devices Agency. Device Bulletin 2002(06). Benchtop steam sterilisers - guidance on purchase, operation and maintenance. London: Medical Devices Agency, 2002

33. Smith A J, Bagg J, Hurrell D, McHugh S. Sterilisation of re-usable instruments in general dental practice. BrDent J 2007; 203: E16. 